\title{
Marriage and mental health
}

Some form of marriage has been a feature of human societies throughout history. Typically, the individuals concerned have been expected to make public their new status, and to accept the community's right to demand conformity with rituals and taboos surrounding this social contract.

But vast and uncontrolled changes in the nature of marriage are taking place in today's South Africa. The proportion of marriages ending in divorce rises inexorably. Serial marriages have become perhaps almost the norm, and cohabitation outside marriage is widespread. Cohabitators make no social contracts of the type mentioned above. Meanwhile, the traditions that brought stability to African societies, already influenced by the marital practices of imported religions, are now increasingly modified by exposure to the ravages of urbanisation. New generations of offspring have emerged from these transitional relationships. It is not at all clear that conventional methods of child rearing will meet their needs, and the current trial-and-error approach has the potential for profound individual and social consequences. Interestingly, until quite recently the production of children was regarded as the main function of marriage, while the current emphasis seems to fall much more on the gratification of adult needs.

However, regardless of how other behavioural scientists approach societal transformations, it is generally accepted that aspects of marriage are among the most profound psychosocial factors affecting patients' emotional and behavioural health and in turn their functionality. So psychiatrists have their own, very specific, reasons to be concerned about the situation.

We are assured in this issue that polygamy '... is not inevitably destined to disappear under the pressures of urbanisation and wage employment'. ' But only a minority of marriages are involved, although perhaps the current trend for individuals to have several marital or marital-type relationships in their life could be seen as a form of serial polygamy.

Similarly, although the Committee of SASOP has issued a statement ${ }^{2}$ welcoming the Constitutional Court's recent legalisation of same-sex marriages, these are probably destined to remain a minority. Of course, the Committee wanted homosexual individuals to benefit from access to human rights previously denied to them. ${ }^{3}$ But it does not follow that the mental health of homosexuals will also benefit from marriage. And, in a clinical context, psychiatrists will not be able to rely on existing data derived from studies of heterosexual marriages, or even data from same-sex unmarried cohabitations. It is to be hoped that the new phenomenon of same-sex marriage will prove to be a fertile subject for research.

Perhaps I am an example of another minority group worthy of research. I have only been married for 43 years and it may be early days yet, but it is beginning to look as if I will end up one of the diminishing number of 'survivors' of what used to be called 'successful marriage'. However, even if we add up all old people who have remained married to one person of the opposite sex, the polygamists and the married homosexuals, they are probably merely diminishing groups of conservatives clinging to minorityhood.

\section{The effects of marital status on mental and physical health}

In any event, we do have a mass of data about marriage of relevance to most of our patients. These data are derived from many thousands of studies that throw some light on possible effects of marital status on mental health. Unfortunately the reported findings are often contradictory, and usually employ unconvincing measuring instruments of mental health, or they are derived from extremely heterogeneous study populations and they must be interpreted with caution. But, in general, research findings do show married individuals to be at reduced risk of mental illness. ${ }^{4}$ Conversely, the incidence of most mental disorders, perhaps all, has consistently been found to be greater in unmarried people, or those who have been in failed marriages.

Also, studies clearly show that married individuals live longer and enjoy better physical and mental health than their non-married counterparts. ${ }^{5}$ But can being married in itself really bestow such major benefits? The findings could be explained by healthy individuals being more attractive mates, or by spouses deserting partners who become ill, even with conditions that cannot be attributed to marital status. Moreover, particularly in major psychiatric disorders such as schizophrenia and bipolar disorder, the nature of the illness is likely to reduce the chance of successful and maintained relationships. Severe personality disorder and early-onset substance abuse can have similar effects. Thus, in these cases, being unmarried is associated with illness, but marriage in itself is not the causative factor.

A fascinating, unusually long-term and comprehensive study ${ }^{6}$ found that men who were born outside of marriage in early 20thcentury Sweden ran a higher risk of dying from ischaemic heart disease in middle and old age than men who were born inside 
marriage. This risk rose to $93 \%$ higher in men who themselves never married. In their complex analysis of these findings the authors concluded that this resulted from the effects of childhood social stigma, compounded in turn by subsequent failure in adulthood to comply with the established norms of society regarding marriage. Of course the subjects of this study, although a huge cohort, were derived from a birth cohort database from one area of Sweden, and even there society's norms will have changed dramatically. But the outcome is entirely compatible with our increased awareness of the relationship between depressive disorders and coronary artery disease. ${ }^{7}$ And that too is believed to be significantly mediated through psychosocial mechanisms. There are similar relationships with, for example, cancer and diabetes and other general medical conditions.

\section{Depression and marital status}

There are various reported interesting relationships between depressive disorders and marital status. ${ }^{8}$ Rates of depression are highest among separated and divorced and widowed persons and lowest among single and married persons. Interestingly, the data may be confounded by the fact that the risk of major depressive disorder appears to vary with gender. Depression is commoner in married than in single women, but the opposite applies to men. However, according to Simon ${ }^{9}$ the gender difference is linked to breakdown of marriage rather than the effects of being married, and it would be premature to rush to recommend that men should marry while women remain single.

\section{Effec ts of manital transitions}

It would in fact be difficult to base any recommendations on the data collected in typical epidemiological studies, which are usually collected in cross-sectional fashion, failing to reflect the quality of the relationships or, even more importantly, the association between any psychiatric symptoms and specific crises within the relationships around the time of the study. In huge numbers of patients, some or other marital transition is clearly intimately associated with mental distress or disorder. ${ }^{10}$ Conversely, some marital transitions help to restore health. For example, dissolution of a difficult marriage may relieve longstanding depressive symptoms.

This is why we elicit the longitudinal history of each patient's relationships, as well as the possible aetiological relevance of their actual marital status at the time of the consultation, before writing their prescriptions for mood stabilisers. (At least I hope we do.) Usually this calls for more than applying a job lot of rating scales. But, transitions such as separation or divorce or death of a partner are ideal concrete endpoints for 'before and after' or 'with and without' direct group comparisons. Unfortunately, the methodologies of most studies in this field frequently seem designed to meet the basic requirements for a pass in a degree module research report, or at best a simple publication. Most fall well short of making fundamental contributions to our understanding of the impacts of these vitally important life events and the mechanisms by which they exercise their effects.

\section{Psyc hiatrists}

Physicians have a higher risk of divorce than other occupational groups. In an American study ${ }^{11}$ psychiatrists were top of the log at $50 \%$, but even for the wooden spoon pathologists the figure was $33 \%$. It is likely that complex factors that influenced the choice of specialty, and also the choice of mate, were more important than the nature of psychiatric practice. But it is surely food for thought.

\section{What about the mental health of offspring?}

In UK, nearly half of all children are now born to unmarried parents and there has been a huge increase in single-parent families. Governmental financial and housing support for single parents may actually in some cases be encouraging young females to choose single motherhood without expectations of any marriage contract. Meanwhile, more and more studies demonstrate ${ }^{12}$ that such children do badly on various measures of health and behaviour. It seems that unmarried parents are five times more likely to split up than married ones and children from broken homes are more likely to be abused, and in turn to become abusers, to run away from home, to be involved in serious truancy, to steal, and to become depressed and to commit suicide. The popular culture of these countries which reflects and probably encourages acceptance of the new social systems, is globally available and a powerful factor in producing similar changes in many parts of the world, including South Africa, to add to local anti-stable marriage factors.

Commitment to marriage is no longer the flavour of the month, at least among heterosexuals. Perhaps the Committee of SASOP could issue a statement about it.

\section{Mike Ewart Smith}

Honorary Clinical Consultant

Division of Psychiatry

University of the Witwatersrand

Johannesburg 


\section{editorial}

1. Moosa MHH, Benjamin R, Jeenah FY. A review of multispousal relationships - psychosocial effects and therapy. South African Journal of Psychiatry 2006; 12: 12 14 (this issue).

2. SASOP. Sasop supports same-sex marriages. South African Journal of Psychiatry 2006; 12: 2

3. Culhane JG. Same-sex marriage: the depth of the opposition and the importance of victory. Journal of the Gay and Lesbian Medical Association 1999; 3: 103-108.

4. Marks NF, Lambert JD. Marital status continuity and change among young and midlife adults: longitudinal effects on psychological well-being. Journal of Family Issues 1998; 19: $652-686$

5. Strohschein L, McDonough P, Monette G, Shao Q. Marital transitions and mental health: are there gender differences in the short-term effects of marital status change? Social Science and Medicine 2005; 61: 2293-2303.

6. Modin B. Born out of wedlock and never married - it breaks a man's heart. Soc Sci
Med 2003; 57: 487-501

7. Ewart Smith M. Depression and coronary artery disease. Journal of Depression and Anxiety 2001 ; May: 22-25.

8. Akiskal H. Mood disorders: introduction and overview. In: Saddock BJ, Saddock VA, eds. Kaplan and Saddock's Comprehensive Textbook of Psychiatry. 7th ed Philadelphia: Lippincott, Williams \& Wilkins, 2000: ch. 14.

9. Simon RW. Revisiting the relationships among gender, marital status, and mental health. American Journal of Sociology 2002; 107: 1065-1091.

10. Zheng $W$, Hart R. The effects of marital and nonmarital union transition on health Journal of Marriage and Family 2002; 64: 420-432.

11. Rollman BL, Mead LA, Wang N-Y, Klag MJ. Medical specialty and the incidence of divorce. N EnglJ Med 1997; 336: 800-803.

12. Wakefield M. Faith and reason. Spectator on Line 2006. http://spectator co.uk/online_pvf.php?id=245 (accessed 1 May 2006). 